Check for updates

Cite this: RSC Adv., 2020, 10, 6960

Received 16th September 2019

Accepted 26th January 2020

DOI: $10.1039 / c 9 r a 07441 d$

rsc.li/rsc-advances

\section{Biomass-derived three-dimensional carbon framework for a flexible fibrous supercapacitor and its application as a wearable smart textile $\dagger$}

\author{
Chunghsuan Hsiao, (D) Chiyoung Lee and Nyanhwa Tai (D)*
}

\begin{abstract}
High electrochemical performance and mechanical reliability are two important properties of the flexible fibrous supercapacitors (FFSCS) used in portable and wearable electronics. Herein, we introduce highperformance and stable FFSCs produced using Tetrapanax papyrifer with a honeycomb-like structure (the key material) acting as a frame for an activated carbon (AC) coating. The honeycomb-like structure facilitates penetration of electrolytes and electron transport in the AC particles. This reduces the contact resistance between the $A C$ and current collector, thereby enhancing the electrochemical energy storage. The FFSCs possess long length and area specific capacitances of $20.8 \mathrm{mF} \mathrm{cm}{ }^{-1}$ and $83.9 \mathrm{mF}$ $\mathrm{cm}^{-2}$, respectively. In addition, the fabricated FFSCs display a maximum length (area) energy density of $3.98 \mu \mathrm{W} \mathrm{h} \mathrm{cm}{ }^{-1}\left(16.1 \mu \mathrm{W} \mathrm{h} \mathrm{cm}{ }^{-2}\right)$ at a power density of $0.07 \mathrm{~mW} \mathrm{~cm}^{-1}\left(1.99 \mathrm{~mW} \mathrm{~cm} \mathrm{~cm}^{-2}\right)$ and attain an excellent capacitance retention of $91 \%$ over 10000 cycles. Moreover, the supercapacitors exhibit excellent mechanical flexibility with minor increase in capacitance upon bending. Three flexible fibrous supercapacitors in series power a red light-emitting diode, demonstrating the potential application of the flexible fibrous supercapacitors in smart textiles.
\end{abstract}

\section{Introduction}

Studies on miniaturized and flexible electronic devices including artificial skin, smart textiles, and flexible/wearable electronics are increasingly emerging because of the urgent demand for next-generation high-performance electronic devices. ${ }^{\mathbf{1 , 2}}$ Thus, the study of flexible fibrous supercapacitors (FFSCs) is attracting much attention. Fibrous supercapacitors usually range from micrometers to millimeters in diameter, with their small size and light weight making them suitable for many innovative applications..$^{3,4}$

FFSCs include active materials like carbon materials, metal oxides, conductive polymers, and MXene, and fiber current collectors such as metal wire, graphene fibers, carbon nanotube (CNT) yarn, and carbon fiber bundles (CFBs).$^{5-14}$ In a recently published article, Z. Wang et al., reported the fabrication of flexible yarn electrodes by biscrolling MXene with CNT yarns. Because of adopting the biscrolling process, a high MXene loading of $\approx 98 \mathrm{wt} \%$ was reported. MXene, with the general formula of $\mathrm{Mn}+1 \mathrm{X}_{n} \mathrm{~T}_{x}$, composed of a transition metal (M), carbon and/or nitrogen (X) and surface termination groups (T), was used in their study and the electrode with high MXene

Department of Materials Science and Engineering, National Tsing Hua University, No. 101, Sec. 2 Kuang-Fu Rd., Hsinchu, 30013, Taiwan, Republic of China.E-mail: nhtai@ mx.nthu.edu.tw; Tel: $+886-3-5715131$ ext. 31026

$\dagger$ Electronic supplementary information (ESI) available. See DOI: 10.1039/c9ra07441d loading and high conductivity of CNT yarn performs an extremely high linear capacitance of $118 \mathrm{mF} \mathrm{cm}^{-1}$. In our work, all-carbon electrode was prepared and a high linear capacitance of $97.81 \mathrm{mF} \mathrm{cm}^{-1}$ is achieved owing to the synergistic effect of the 3D carbon framework of the carbonized TC paper and the high specific surface area of the AC. In addition, carbon fibers with low density, excellent conductivity, and good mechanical properties are promising as the ESI $\dagger$ for FFSCs.

Compared with metal oxides, active carbon materials including AC, onion-like carbon, carbide-derived carbon, CNTs, and graphene sheets are frequently utilized in FFSCs. This is because of their high specific surface area, electrical conductivity, high rate capability, and excellent cycling stability. The properties of the carbon materials facilitate their application in devices requiring reversible ion adsorption/desorption during operation.

Most novel carbon materials are expensive, and their fabrication is environmentally unfriendly. In contrast, AC is widely used in supercapacitors, and it is available for massive and economic production. Harrison et al. fabricated a coaxial single wire supercapacitor with length and area specific capacitances of $0.1 \mathrm{mF} \mathrm{cm}^{-1}$ and $3.18 \mathrm{mF} \mathrm{cm}^{-2}$, , $^{15}$ respectively. However, the nonuniform dispersion of AC causes the supercapacitor to exhibit low efficiency. This is further explained by the low charge transfer rate from the AC to the current collectors, producing a significant decrease in efficiency of the electrical double layer capacitor (EDLC). 
A possible solution to problems arising is the combination of the AC with wearable/knittable conductive fibers to maintain good capacitive energy storage properties. However, there are only few reports in order to address these problems. Published studies on FFSCs focus on the development of materials with high specific surface area.

Generally, most of the amorphous carbon which derived from natural sources are grinded into powder, therefore, it may lose its three-dimensional (3D) framework structure. The Tetrapanax papyrifer (Tong Cao, TC) pith can be easy cut into paper, therefore, the grinding is not required for the fabrication of electrodes, as a result, it can retain its 3D structures.

The aim of this research is to maintain the 3D framework structures of plant while preparing the electrodes, therefore, the electrolyte can more easily infiltrate to the electrode, thereby improving the energy storage efficiency.

Herein, we propose a novel method to fabricate low-cost, high-performance, and flexible textile FFSCs by utilizing CFBs as the current collector and carbonized TC paper possessing a $3 \mathrm{D}$ carbon framework coated with commercial AC as the activated material. The 3D carbon framework provides interconnected pathways for electron transfer and enhances the ion transfer capability. ${ }^{\mathbf{1 6}}$ More importantly, the AC can be distributed uniformly on the framework through the proposed method.

The excellent mechanical properties and electrical conductivity of CFBs, in conjunction with the good electrical conductivity of the carbonized TC and the high surface area of the AC resulted in exceptional electrochemical properties of FFSCs. The properties include a high specific capacitance (20.8 $\mathrm{mF} \mathrm{cm}^{-1}$ or $\left.83.9 \mathrm{mF} \mathrm{cm}^{-2}\right)$, a high energy density $(3.98 \mu \mathrm{W}$ $\mathrm{h} \mathrm{cm}^{-1}$ or $16.1 \mu \mathrm{W} \mathrm{h} \mathrm{cm}{ }^{-2}$ ), and a power density of up to 0.07 $\mathrm{mW} \mathrm{cm} \mathrm{cm}^{-1}$ (or $1.99 \mathrm{~mW} \mathrm{~cm}^{-2}$ ) at a current of $0.1 \mathrm{~A} \mathrm{~g}^{-1}$. The fabricated FFSCs also exhibit long life stability, retaining a specific capacitance of $91 \%$ after 10000 test cycles.

\section{Materials and fabrication method}

\subsection{Preparation of TC pith paper and TC powders}

TC pith paper was prepared by cutting pith from the stalk of the TC plant into long strips $\sim 200 \mu \mathrm{m}$ thick with an area of $3 \times 150$ $\mathrm{mm}^{2}$. TC powders (TCp) were then obtained by grinding the carbonized TC pith into powders.

\subsection{Synthesis of the activated carbon slurry and tong cao powders slurry}

Polyvinylidene fluoride (PVDF, $0.8 \mathrm{~g}$ ) was dissolved in $40 \mathrm{~mL}$ of $N$-methyl-2-pyrrolidone; subsequently, $2.4 \mathrm{~g}$ of AC (or TCp) and $0.8 \mathrm{~g}$ of XC-72 carbon black were added to the solution and mixed by magnetic stirring for an hour.

\subsection{Electrode preparation}

The starting materials for the electrode comprised TC pith paper, CFB, TCp, and AC slurry, and the fabrications of TC pith paper, TC-CFB, and AC-TC-CFB are schematically shown in Fig. 1. Conversely, a long CFB containing 3000 fibers in a bundle was cut into pieces $\sim 60 \mathrm{~mm}$ long. The TC pith paper was dipped into a molasses solution $\left(0.4 \mathrm{~g} \mathrm{~mL}^{-1}\right)$ and then wrapped around the CFB, followed by drying at $80{ }^{\circ} \mathrm{C}$ in an oven for $10 \mathrm{~min}$. The molasses solution acted as the carbon precursor and the binder between the CFB and the TC. Subsequently, the CFB wrapped by the TC paper containing the molasses solution was placed in a tube furnace. This was then carbonized in $\operatorname{Ar}(1000 \mathrm{sccm})$ at $700{ }^{\circ} \mathrm{C}, 800{ }^{\circ} \mathrm{C}$, and $900{ }^{\circ} \mathrm{C}$ using a heating rate of $20{ }^{\circ} \mathrm{C} \mathrm{min}{ }^{-1}$, and held isothermally at the designed temperature for $1 \mathrm{~h}$ at 1 atm; the electrodes carbonized at $700{ }^{\circ} \mathrm{C}, 800{ }^{\circ} \mathrm{C}$, and $900{ }^{\circ} \mathrm{C}$ were designated as TC700-CFB, TC800-CFB, and TC900-CFB, respectively.

The CFB and the TC800-CFB were dipped separately into an AC slurry while another CFB was dipped into a TCp slurry, and all the specimens were dried overnight in an oven at $120^{\circ} \mathrm{C}$. The fabricated electrodes were designated as AC-CFB, AC-TC800CFB, and TCp-CFB, respectively.

\subsection{FFSC fabrication}

The gel electrolyte was prepared by dissolving $3 \mathrm{~g}$ of polyvinyl alcohol (PVA) in a solution containing $3 \mathrm{~g}$ of $\mathrm{H}_{3} \mathrm{PO}_{4}$ (85 wt\%) and $30 \mathrm{~mL}$ of deionized water and stirring at $80{ }^{\circ} \mathrm{C}$ until the solution was clear. Two AC-TC800-CFB electrodes were separately coated with a gel electrolyte $\left(\mathrm{PVA}-\mathrm{H}_{3} \mathrm{PO}_{4}\right)$ via a dipcoating process and wrapped with a nonwoven polyester fabric acting as a spacer. The two electrodes with electrolyte were interlaced and inserted into a heat-shrinkable tube that was subsequently subjected to hot air; consequently, the tube diameter was reduced to host the two electrodes.

\subsection{Characterizations and instrumentation}

The morphologies of the AC, CFB, and TC samples were studied using a field emission scanning electron microscope (SEM, JEOL JSM-6500F). A Raman spectrometer (Horiba HR800 UV) and an X-ray diffractometer (XRD, Shimadzu XRD 6000) were used to analyze the microstructures. The surface chemistry of the TC samples was examined by an X-ray photoelectron spectrometer (XPS, Ulvac-PHI PHI 1600). A Brunauer-Emmett-Teller analyzer (BET, Micromeritics TriStar II Series2) was applied to measure the pore size distribution. Cyclic voltammetry (CV), electrochemical impedance spectroscopy (EIS), and galvanostatic charge-discharge (GCD) were performed by a potentiostat/galvanostat system (Metrohm/Eco Chemie PGSTAT30) to assess the electrochemical performance of the electrodes and the FFSCs.

\section{Results and discussion}

The color of the TC pith paper changed from white to black after heating at elevated temperatures, highlighting carbonization. The XRD patterns display two broad diffuse bands centered around $2 \theta=23^{\circ}$ and $43^{\circ}$ (Fig. 2a) that are associated with crystalline diffraction of the (002) and the (100) planes of graphite, respectively. This suggests that the TC pith paper possesses a low-degree graphitic crystal structure, with the star symbol representing a mineral from the TC plant. 
(a)

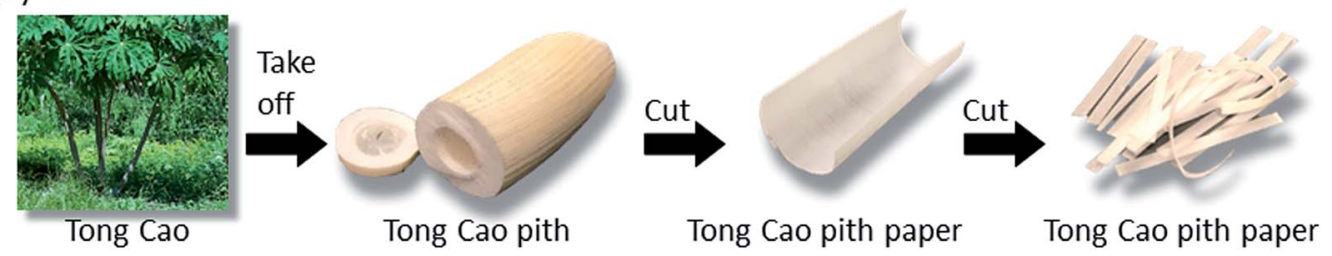

(b)

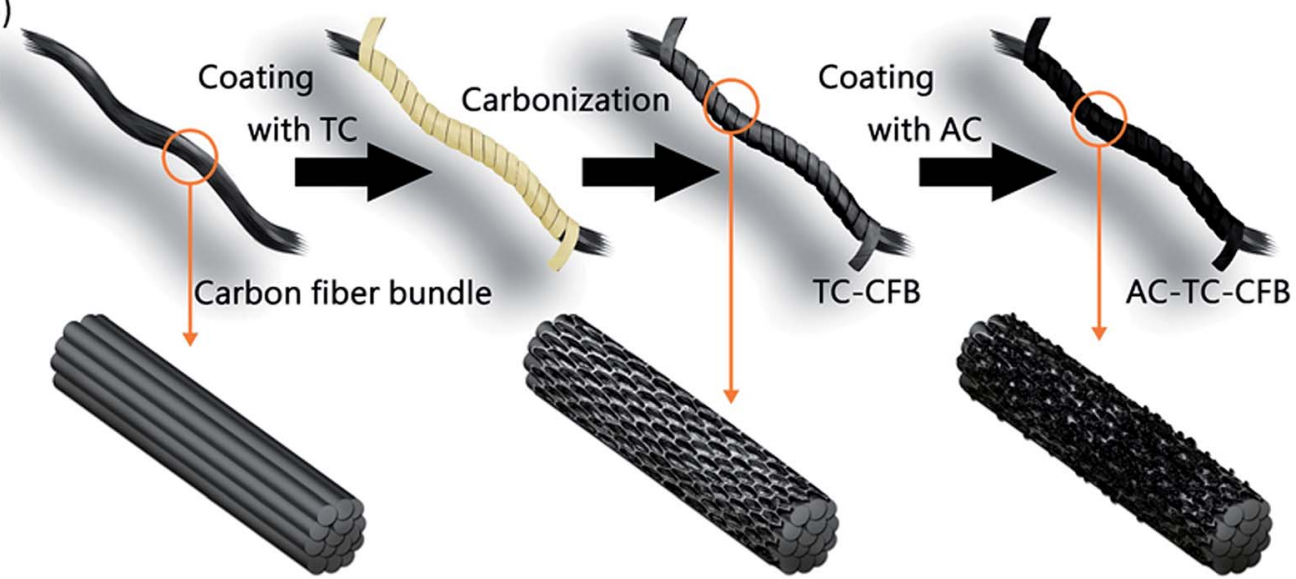

Fig. 1 Schematic diagram illustrating the preparation of (a) TC pith paper and (b) TC-CFB and AC-TC-CFB.

Further analyses of the microstructures of the TC pith paperderived carbon were conducted using Raman spectroscopy (Fig. 2b). The Raman spectra of the TC700, TC800, and TC900 samples exhibit typical peaks at $1330 \mathrm{~cm}^{-1}$ and $1580 \mathrm{~cm}^{-1}$, assigned as the D band and $\mathrm{G}$ band, respectively. The D band is in reference to the disordered structure of graphite ( $\mathrm{sp}^{3}$ type),
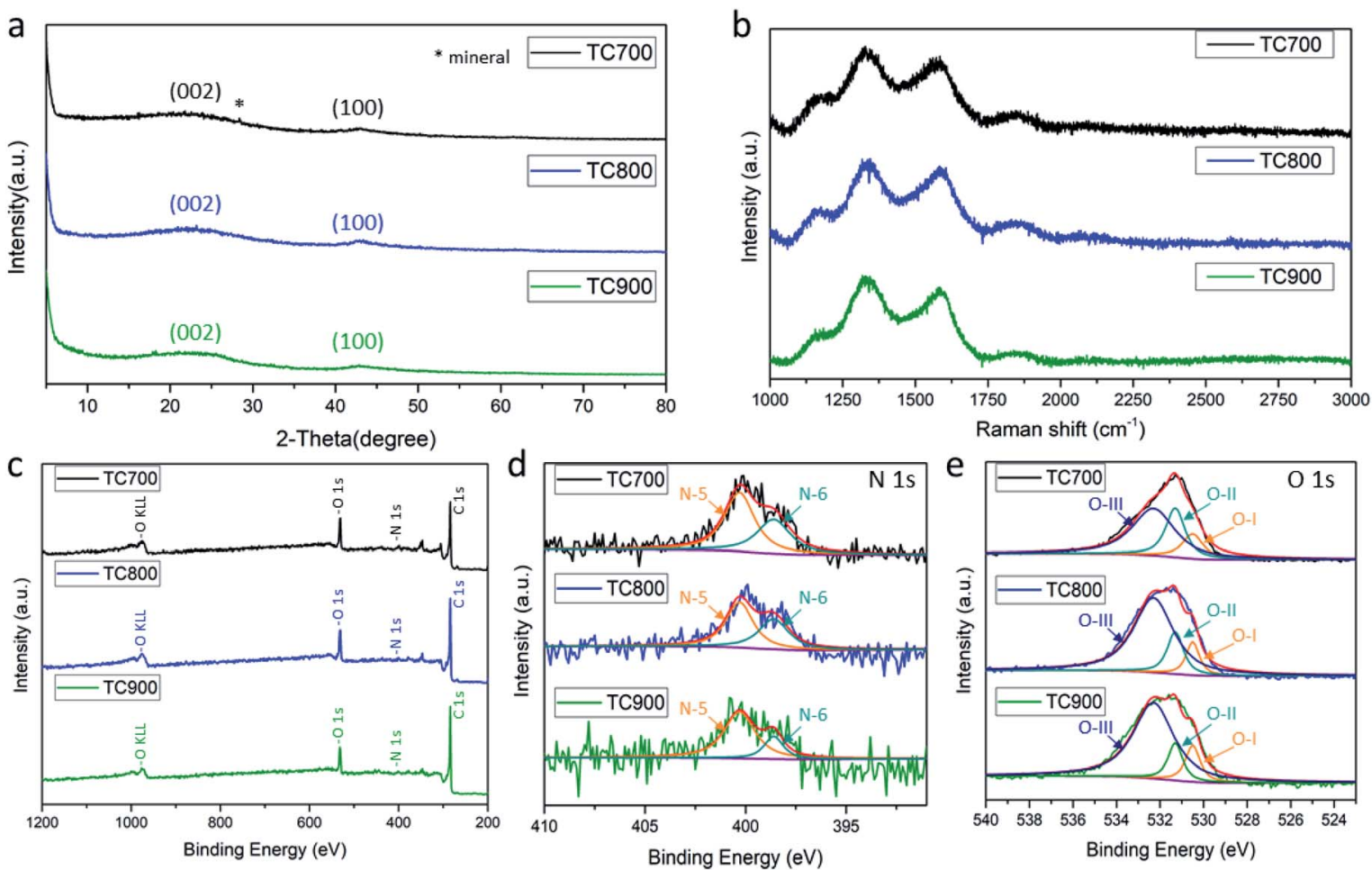

Fig. 2 (a) XRD patterns and (b) Raman spectra of the TC sheets treated at different temperatures, (c) full range XPS spectra, (d) high-resolution N 1s spectra, and (e) high-resolution $\mathrm{O}$ 1s spectra of the TC sheets treated at different temperatures. 
whereas the $\mathrm{G}$ band is attributed to $\mathrm{C}-\mathrm{C}$ bond stretching of the prefect graphitic structure ( $\mathrm{sp}^{2}$ type). The $I_{\mathrm{D}} / I_{\mathrm{G}}$ ratio represents the degree of graphitization; a low ratio indicates a better graphitic microstructure for the carbon material. As the carbonization temperature increases, the carbon material shows higher degree of graphitization, as demonstrated by $I_{\mathrm{D}} / I_{\mathrm{G}}$ ratios of 1.18, 1.13, and 1.11 for TC700, TC800, and TC900 samples, respectively.

The full-range XPS spectra of TC700, TC800, and TC900 for O $1 \mathrm{~s}$ and $\mathrm{N} 1 \mathrm{~s}$ are shown in Fig. $2 \mathrm{c}$, with the peaks attributed to functional groups of the carbonized molasses. The highresolution $\mathrm{N}$ 1s spectrum depicted in Fig. $2 \mathrm{~d}$ shows peaks at 400.3 and $398.6 \mathrm{eV}$, corresponding to $\mathrm{N}-5$ and $\mathrm{N}-6$, respectively. ${ }^{10}$ All samples presenting peaks at 530.5, 531.3, and $532.3 \mathrm{eV}$ for the $\mathrm{O} 1 \mathrm{~s}$ spectra corresponding to O-I (quinone), OII (phenol/ether), and O-III (carboxylic groups/water), respectively, are shown in Fig. 2e. Among the carbon materials, the TC700 shows the highest nitrogen and oxygen contents of $2.13 \%$ and 15.71 at $\%$, respectively (Table 1). Nevertheless, TC700 was not adopted as the primary sample for investigation in this work because its high electric resistivity may negatively impact capacitance.

The presence of nitrogen-doped and oxygen functional groups creates a disordered structure in the TC pith paperderived carbons. As the carbonization temperature increases, the carbon material becomes more ordered, indicating a better electric conductivity.

A photograph and a SEM image of the TC pith paper are shown in Fig. 3a and b, respectively. The TC pith paper is easily processed into any shape with its flexibility maintained (inset Fig. 3a). Interestingly, the TC pith paper exhibits a honeycomblike structure with a hole size between 100 and $150 \mu \mathrm{m}$ (Fig. 3b).

An FESEM image of a CFB containing 3000 fibers (3 K CFB), with a bundle diameter of $500 \mu \mathrm{m}$, a density (mass per length) of $2 \mathrm{mg} \mathrm{cm}^{-1}$, and an electrical conductivity of approximately 5.6 $\times 10^{4} \mathrm{~S} \mathrm{~m}^{-1}$ is shown in Fig. 3c. The CFB morphologies before and after coating with the AC slurry are depicted in Fig. $3 \mathrm{c}$ and $\mathrm{d}$, respectively. The diameter of the AC-CFB increased to $750 \mu \mathrm{m}$ (inset, Fig. 3d) after incorporation the AC particles containing nanometric to micrometric pores. The inset in Fig. 3e illustrates a macroscopic view of the CFB wrapped in TC pith paper after carbonization. The magnified image of the TC-CFB in Fig. 3e represents a honeycomb-like structure like the original TC structure, providing a high surface area for AC deposition. The TC-CFB diameter is approximately $600 \mu \mathrm{m}$, and molasses was

Table 1 Surface chemical composition and resistance of the TC sheets prepared at different temperatures (atomic percentages are obtained from the XPS analyses)

\begin{tabular}{lllll}
\hline & \multicolumn{3}{l}{ Atomic concentration (at\%) } & \\
\cline { 2 - 3 } Sample & C 1s & N 1s & O 1s & Resistance $(\Omega)$ \\
\hline TC700 & 82.16 & 2.13 & 15.71 & 14.4 \\
TC800 & 84.65 & 1.52 & 13.83 & 2.2 \\
TC900 & 87.92 & 1.13 & 10.95 & 0.8
\end{tabular}

used to bind the TC pith paper to the CFB before carbonization. The carbonized molasses provided a charge transfer network between the TC and CFB and strengthened the TC structure. More importantly, we observed uniform deposition of AC particles onto the surface of the concave TC structure (shown by arrows in Fig. 3f). Magnified images of the CFB and the TC-CFB coated with AC are displayed in Fig. $3 \mathrm{~d}$ and f, respectively. Evidently, uniform deposition of the AC particles on the TC-CFB without agglomeration is possible. However, this is not possible without the TC pith paper, suggesting that the TC pith paper and the molasses enhanced adhesion of the AC particles onto the TC pith paper. The AC-TC-CFB yielded an approximate thickness of $850 \mu \mathrm{m}$ (inset Fig. 3f).

The $\mathrm{N}_{2}$ adsorption-desorption isotherms and the pore size distributions for the AC, AC-TC, and TC powder are displayed in Fig. 4a and b, respectively. Generally, the hysteresis loop at relative pressures $\left(P / P_{0}\right)$ from 0.4 to 1.0 in the adsorptiondesorption isotherms indicates the presence of mesopores (2$50 \mathrm{~nm})$ and macropores $(>50 \mathrm{~nm})$. In addition, the AC exhibits a typical Type I isotherm (Fig. 4a), characterized by rapid adsorption at pressures $<0.2$, representing micropores from 1.6 to $3.0 \mathrm{~nm} .{ }^{17,18}$ The calculated specific surface areas are 1425.2, 470.2 , and $44.2 \mathrm{~m}^{2} \mathrm{~g}^{-1}$ for AC, AC-TC800, and TC800, respectively. The low specific surface area $\left(44.2 \mathrm{~m}^{2} \mathrm{~g}^{-1}\right)$ of the TC800 powder explains the low specific capacitance of $3.2 \mathrm{~F} \mathrm{~g}^{-1}$ at $100 \mathrm{mV} \mathrm{s}^{-1}$ for the TCp-CFB electrode (Fig. S1 $\mathrm{b}_{\dagger}$ ). Interestingly, the specific capacitance of TC800-CFB, incorporating the honeycomb-like structure of the TC and high electric conductivity of the CFB is $120.0 \mathrm{~F} \mathrm{~g}^{-1}$ at $100 \mathrm{mV} \mathrm{s}^{-1}$ (Fig. S1a†). The observed difference is because agglomeration of the powder provides a negative effect on capacitance by hindering infiltration of the electrolyte into the powder cluster. In addition, the boundary within the cluster increases contact resistance.

\subsection{Electrochemical performance of the fabricated electrodes}

The electrochemical properties of the TC-CFB electrodes treated at different temperatures (denoted as TCX00-CFB, where X00 is the carbonization temperature) were evaluated using a threeelectrode system containing a $1 \mathrm{M} \mathrm{H}_{2} \mathrm{SO}_{4}$ solution (Fig. S2a$\mathrm{c} \dagger)$. The TC-CFB electrode exhibited nearly rectangular CV curves at a low scan rate of $20 \mathrm{mV} \mathrm{s}^{-1}$ as well as at higher scanning rates of 60 and $100 \mathrm{mV} \mathrm{s}^{-1}$, demonstrating an ideal capacitive behavior. This behavior probably results from the good electric conductivity of the electrode attributed to the tight contact between TC and CFB that is beneficial for rapid electron transport. Similar results emerge from the GCD curves with typical triangular shapes measured at a current density of $0.2 \mathrm{~A} \mathrm{~g}^{-1}$ (Fig. S2d $\dagger$ ). The equivalent series resistance (ESR) values of the TC700-CFB, TC800-CFB, and TC900-CFB electrodes calculated based on the voltage drop (IR drop) in the GCD curves (Fig. S2d $\dagger$ ) are 39.3, 20.7, and $31.7 \Omega$, respectively. The high specific capacitance of the TC800-CFB electrode (Fig. S2e $\dagger$ ) is attributed to the synergistic effect of oxygen functional groups and its relatively low electric resistance. ${ }^{19-21}$ 

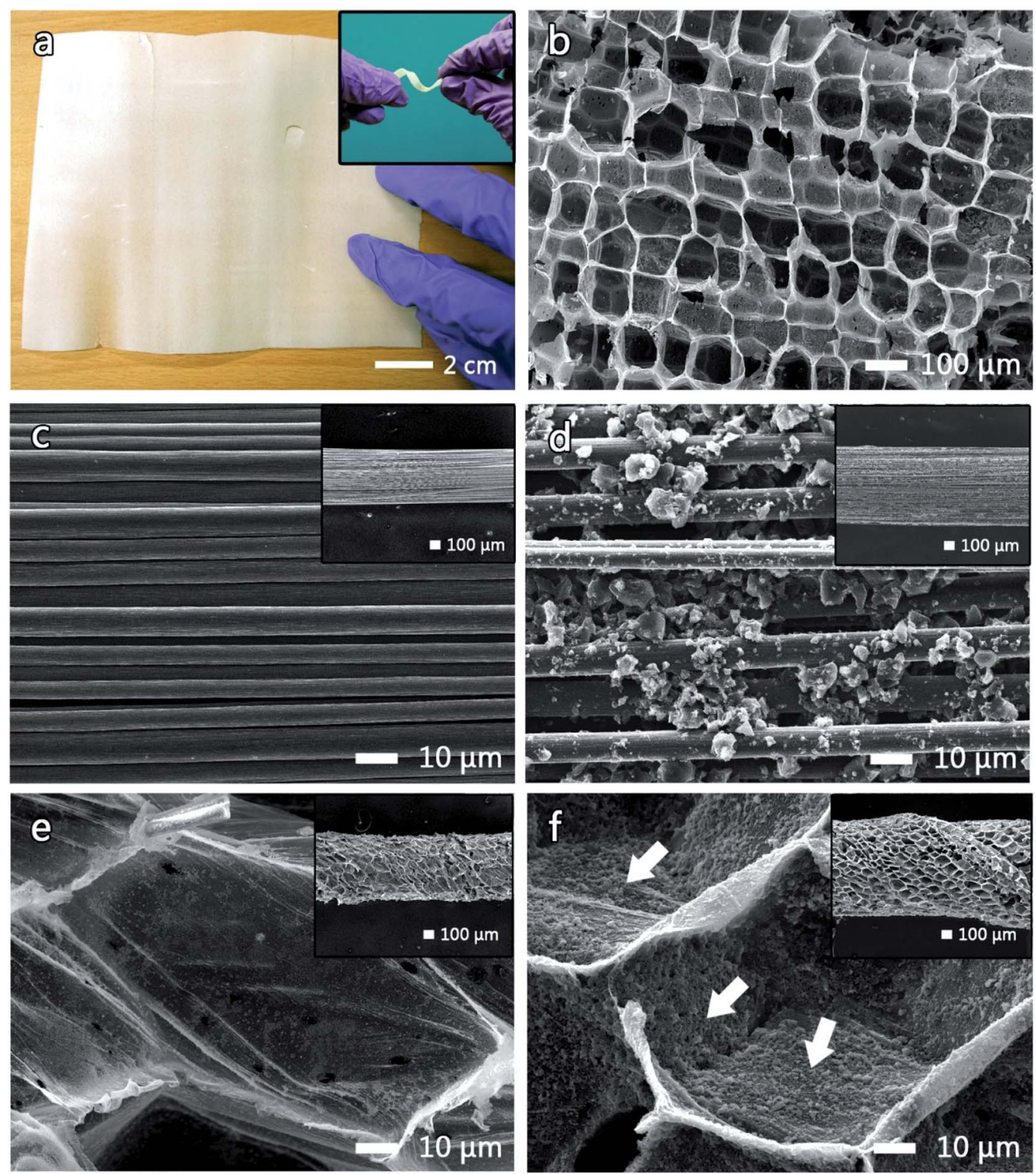

Fig. 3 (a) Photo of a TC sheet with the inset of (a) showing a distorted TC ribbon. Morphologies of (b) a TC sheet surface, (c) a bare CFB, (d) ACCFB, (e) TC-CFB, and (f) AC-TC-CFB.

Usually, the amount of active material used in FFSCs is small, and therefore, the capacitance per unit mass is an improper index for evaluation of the capacitive properties of an electrode. The capacitance per unit space seems more suitable for the evaluation of the capacitive properties of an electrode. Thus, the length capacitance, areal capacitance, and volumetric capacitance are more meaningful for the capacitance evaluation. The specific capacitances of the TC-CFB electrodes treated at $700{ }^{\circ} \mathrm{C}, 800{ }^{\circ} \mathrm{C}$, and $900{ }^{\circ} \mathrm{C}$ and tested at a scan rate of $20 \mathrm{mV}$ $\mathrm{s}^{-1}$ are presented in Table 2 , which were calculated using the equations given in the section of ESI. $\dagger$

Based on the results shown in Table 2, we adopted the TC800-CFB sample penetrated by the AC slurry and dried (ACTC800-CFB) as the typical electrode for evaluation of the capacitive performance of the fabricated electrodes. The CV and GCD curves along with EIS results were used to evaluate the capacitive properties of the bare CFBs, AC-CFB, TC800-CFB, and AC-TC800-CFB. The CV curves (measured at a scan rate of $20 \mathrm{mV}$ $\mathrm{s}^{-1}$ ) at potentials ranging from 0 to $1.0 \mathrm{~V}$ and the GCD curves (measured at a fixed current density of $0.2 \mathrm{~A} \mathrm{~g}^{-1}$ ) at potentials ranging from 0 to $1.0 \mathrm{~V}$ are shown in Fig. $5 \mathrm{a}$ and b, respectively. The GCD curves display an almost symmetrical triangle shape, highlighting a typical feature of good EDLC behavior. The larger CV and GCD area of the AC-TC800-CFB compared with the others suggest that the presence of the AC created a 3D carbon framework that subsequently enhanced the EDLC efficiency of the electrode. 
a

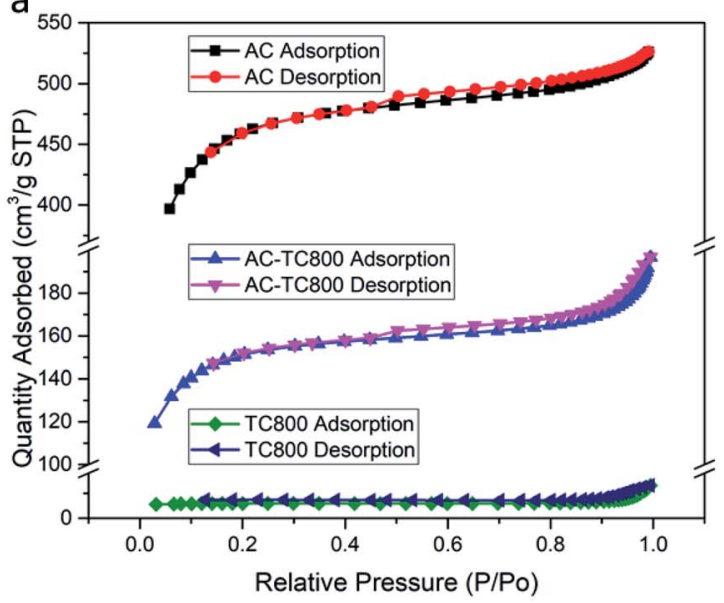

b

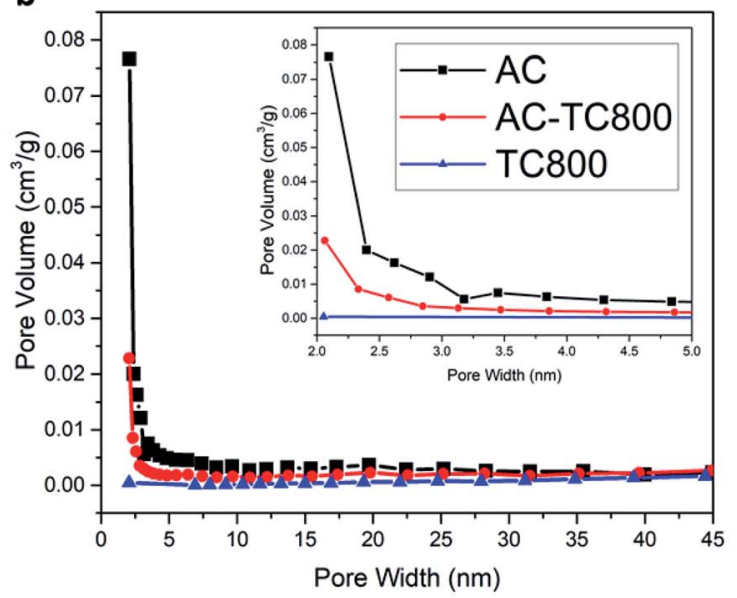

Fig. 4 (a) $\mathrm{N}_{2}$ adsorption-desorption isotherms and BET surface areas and (b) pore size distribution curves based on the Barrett-Joyner-Halenda calculation for AC, AC-TC800, and TC800.

The gravimetric capacitances for the active materials $\left(C_{\text {mass }} * *\right)$ obtained from the CV curves at different scan rates $(20-100 \mathrm{mV}$ $\mathrm{s}^{-1}$ ) are shown in Fig. S3. $\dagger$ Compared with other electrodes, the AC-TC800-CFB electrode has the highest $C_{\text {mass** }}$ of $244.51 \mathrm{~F} \mathrm{~g}^{-1}$ for a scan rate of $20 \mathrm{mV} \mathrm{s}^{-1}$. The specific capacitances per unit length, area, and volume for the AC-TC800-CFB at a scan rate of $20 \mathrm{mV} \mathrm{s}^{-1}$ are presented in Table 3. The capacitance of the ACTC800-CFB is higher than that of the sum of the AC-CFB and TC-CFB. This high capacitance is attributed to a synergistic effect of the 3D carbon framework of the carbonized TC paper and the high specific surface area of the AC. Specifically, the agglomeration of AC in AC-CFB is alleviated, improving the low specific surface area of the TC-CFB.

In addition, AC coating on TC provides more surface area and prevents agglomeration of $\mathrm{AC}$ in the electrode, consequently increasing the surface area for the electric double layer. Furthermore, the CFB with high electric conductivity acted as an excellent current collector for fast electron transfer.

The Nyquist plots of the supercapacitors using AC-CFB, TCCFB, and AC-TC-CFB as electrodes are shown in Fig. 5d. The plot helps in analyzing the EIS data and constructing the equivalent circuits of the electrodes (inset (i) of Fig. 5 c). Herein we used two models to simulate the electrodes including one for the AC-CFB and another for the TC-CFB and AC-TC-CFB. As displayed in Fig. 5d, the simulation results match very well the experimental results. The electrode structures, with or without incorporation of TC in the electrode, are illustrated in Fig. 5e.

As shown in the high-frequency region of the inset in Fig. 5d, the $x$-intercept of the Nyquist plot, denoted as $R_{\mathrm{s}}$, represents the ESR of the electrode. The low $R_{\mathrm{S}}$ of $11.85,14.22$, and $11.13 \Omega$ obtained for AC-CTB, TC-CFB, and AC-TC-CFB, respectively, imply low solution resistance of the electrolytes and electric resistance of the electrodes. The constant phase element 1 (CPE1) and CPE2 depicting the double layer capacitance appear in the equivalent circuits of AC-CFB and AC-TC-CFB shown in the inset in Fig. 5c. Double layer capacitance occurs at interfaces between ionic solutions and electrodes. The diameter of the distorted semicircle highlights the electrode conductivity and the charge transfer resistance $\left(R_{1}\right)$ of the electrode/electrolyte interface. The large value of fitted value of $R_{1}$ of $4.38 \Omega$ for the AC-CFB compared with $1.94 \Omega$ for the TC-CFB and $2.96 \Omega$ for ACTC-CFB is attributed to the binder used in slurry.

In the intermediate-frequency region, the resistance $\left(R_{2}\right)$ is related to the ion transport barrier created by the agglomerated AC particles and the contact resistance among AC particles. The straight line in the Nyquist plots in the low-frequency region signifies the Warburg resistance $\left(W_{1}\right)$ resulting from ion diffusion in the nonuniform microstructure of the AC-CFB, TC-CFB, and AC-TC-CFB electrodes. However, the Nyquist plots of the AC-CFB electrode demonstrate a linear behavior in the low-frequency

Table 2 Electrochemical performances of the TC-CFB electrodes treated at different temperatures ${ }^{a}$

\begin{tabular}{llclll}
\hline Sample & $C_{\text {mass* }}\left(\mathrm{F} \mathrm{g}^{-1}\right)$ & $C_{\text {mass** }}\left(\mathrm{F} \mathrm{g}^{-1}\right)$ & $C_{\text {length }}\left(\mathrm{mF} \mathrm{cm}^{-1}\right)$ & $C_{\text {area }}\left(\mathrm{mF} \mathrm{cm}^{-2}\right)$ & $C_{\text {volume }}\left(\mathrm{F} \mathrm{cm}^{-3}\right)$ \\
\hline TC700-CFB & 18.60 & 96.11 & 38.45 & 196.37 & 50.39 \\
TC800-CFB & 25.18 & 130.10 & 52.04 & 265.82 & 68.21 \\
TC900-CFB & 14.72 & 76.04 & 30.41 & 155.35 & 39.87
\end{tabular}

${ }^{a} C_{\text {mass* }}$ and $C_{\text {mass**: }}$ mass specific capacitances calculated based on the electrode weight and the weight of activated material, respectively; $C_{\text {length }}$ :

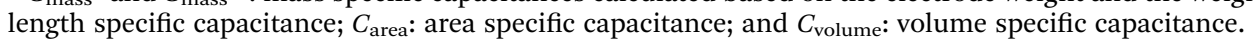



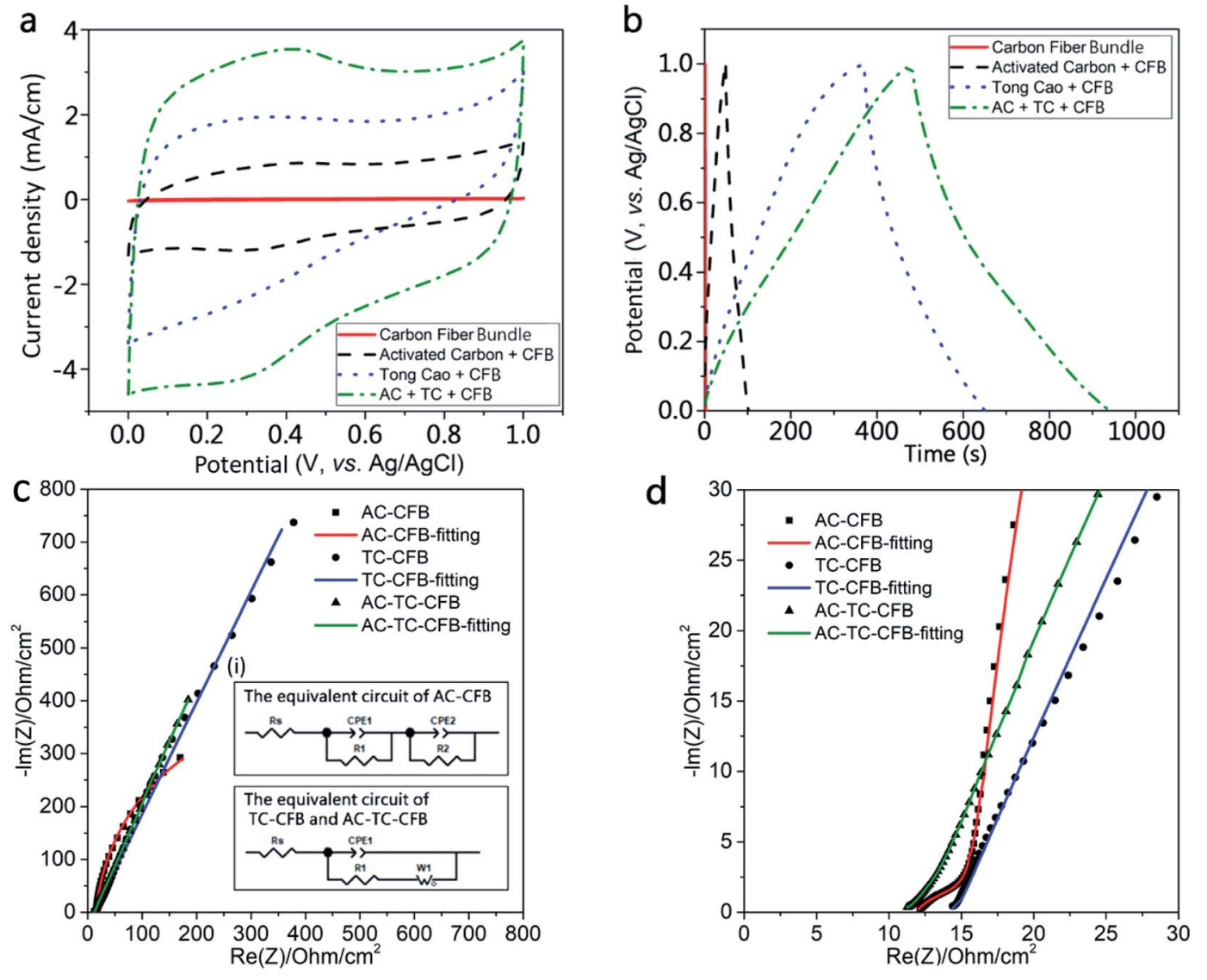

e
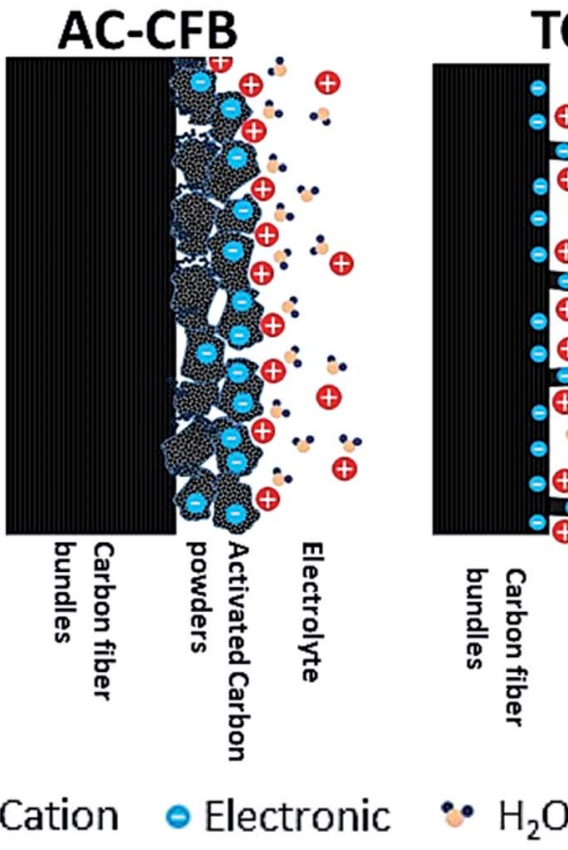

TC-CFB
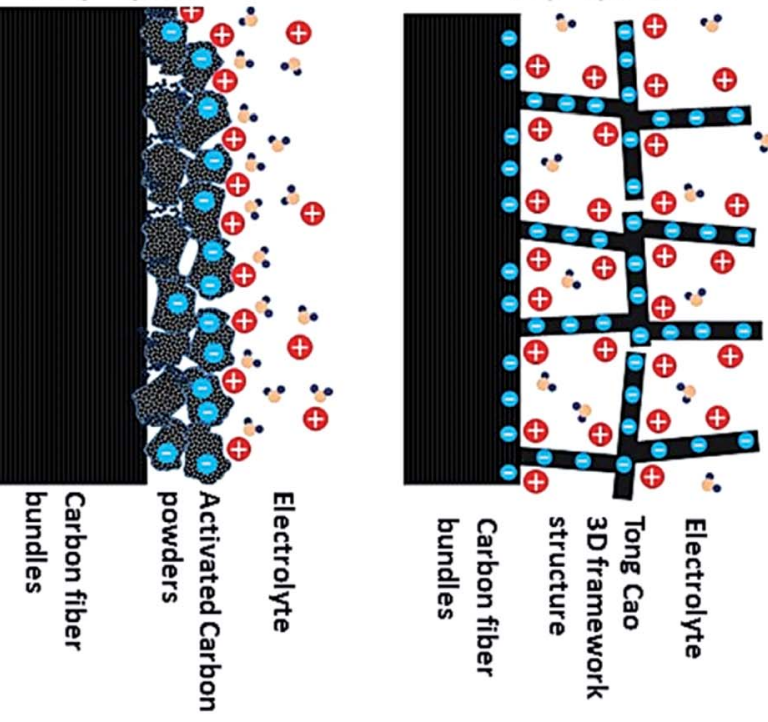

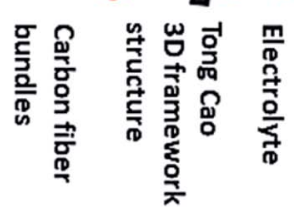

AC-TC-CFB
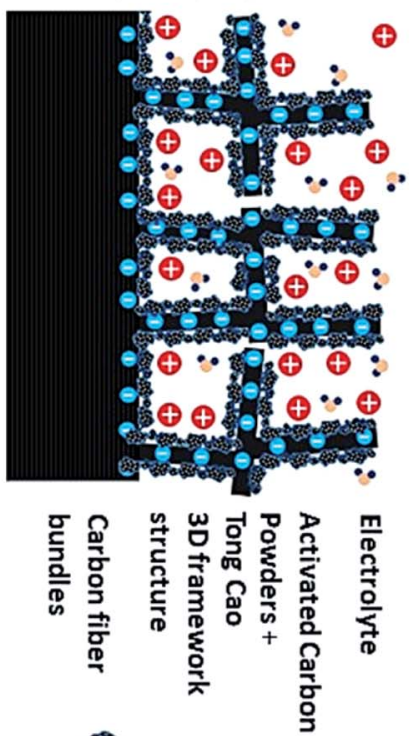

\section{Carbon black \\ Cation \\ - Electronic}

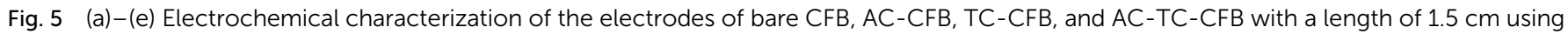

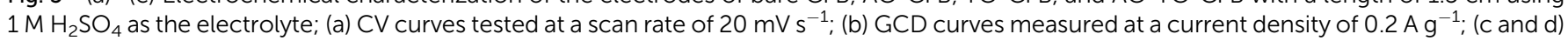

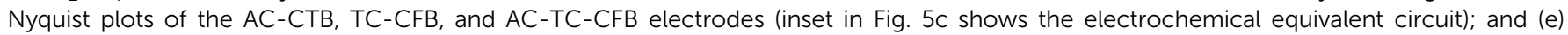
schematic illustration of the AC-CFB, TC-CFB, and AC-TC-CFB electrodes.

region and nonlinear behavior at a relatively higher frequency, indicating that the agglomeration of AC particles restricts diffusion of electrolyte ions in the electrode.
The obtained results suggest that because of the synergistic effect and 3D framework of the AC-TC-CFB electrode, the electrolyte easily infiltrates the electrode, enhancing its capacitance. 
Table 3 Summary of the electrochemical performances of various electrodes ${ }^{a}$

\begin{tabular}{|c|c|c|c|c|c|}
\hline Sample & $C_{\text {mass* }}\left(\mathrm{F} \mathrm{g}^{-1}\right)$ & $C_{\text {mass** }^{* *}}\left(\mathrm{~F} \mathrm{~g}^{-1}\right)$ & $C_{\text {length }}\left(\mathrm{mF} \mathrm{cm}^{-1}\right)$ & $C_{\text {area }}\left(\mathrm{mF} \mathrm{cm}^{-2}\right)$ & $C_{\text {volume }}\left(\mathrm{F} \mathrm{cm}^{-3}\right)$ \\
\hline CFB & 0.21 & 0.21 & 0.34 & 2.13 & 0.67 \\
\hline AC-CFB & 10.80 & 34.48 & 26.20 & 111.69 & 23.92 \\
\hline AC-TC800-CFB & 47.33 & 244.51 & 97.81 & 395.18 & 80.22 \\
\hline
\end{tabular}

${ }^{a} C_{\text {mass* }}, C_{\text {mass** }}, C_{\text {length }}, C_{\text {area }}$, and $C_{\text {volume: }}$ specific capacitances calculated based on the electrode weight, weight of activated material, length, area, and volume, respectively.

The CV curves obtained from the tests at scan rates of 2$200 \mathrm{mV} \mathrm{s}^{-1}$ (Fig. 6a) display quasi-rectangular shapes, especially at low scan rates, indicating that the AC-TC800-CFB exhibits typical EDLC characteristics. The obvious redox peaks likely originate from functional groups including hydroxyl, carbonyl, and carboxyl in the electrode associated with the adoption of molasses as the starting material for the carbon material. ${ }^{22}$ In addition, the XPS results, demonstrating low density $\mathrm{N}$ doping in the electrode, contributed to the pseudo-capacitance, and therefore enhanced its capacitance.

As depicted in Fig. 6b, the GCD performances, measured at current densities of $0.1-2.0 \mathrm{~A} \mathrm{~g}^{-1}$ show symmetric triangular shapes. This suggests fast charge/discharge properties and an ideal capacitive behavior for the AC-TC800-CFB electrode. Notably, a small IR drop (0.0198 V) is observed at a charge/discharge current density of $0.2 \mathrm{~A} \mathrm{~g}^{-1}$, implying a low internal resistance.

The specific capacitance of the AC-TC800-CFB electrode (Fig. 6c) attains high values of 466.84 and $90.36 \mathrm{~F} \mathrm{~g}^{-1}$ from calculations based on the weight of the activated material and electrode, respectively. The capacitance calculated in terms of electrode length $\left(C_{\text {length }}\right)$, area $\left(C_{\text {area }}\right)$, and volume $\left(C_{\text {volume }}\right)$ for the AC-TC800-CFB based on scan rates from 2 to $200 \mathrm{mV} \mathrm{s}^{-1}$ are shown in Fig. 6d. The calculations based on the CV and GCS curves are provided in the experimental section.

\subsection{Electrochemical performance of the FFSCs}

The fabricated FFSCs comprise two fiber electrodes, a spacer, and an electrolyte (Fig. 7a). Two commercial CFBs used as
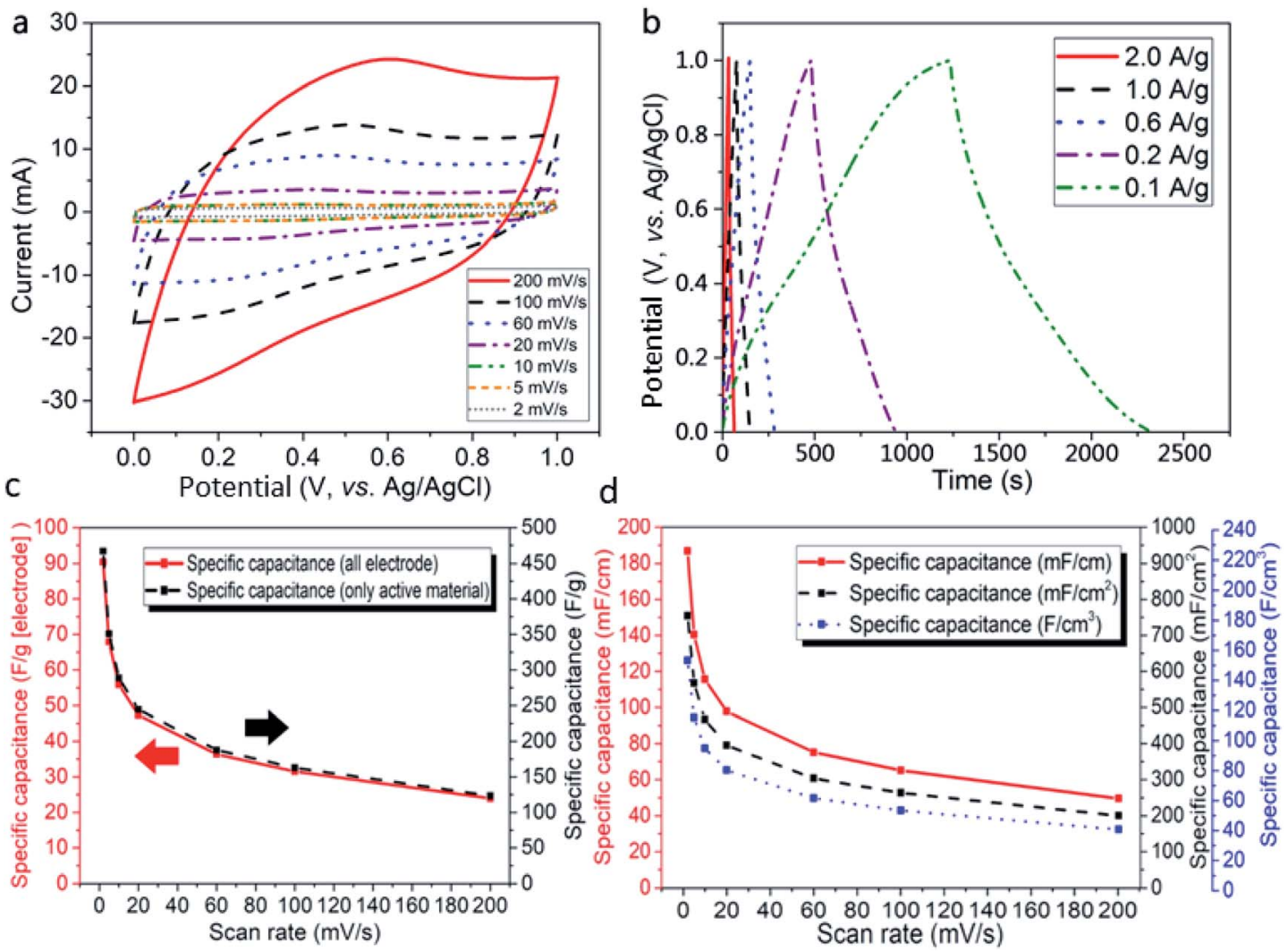

Fig. 6 Electrochemical characterization of the AC-TC800-CFB electrode with a length of $1.5 \mathrm{~cm}$, a mass of all electrodes of $3 \mathrm{mg}$, a mass of active material of $0.7 \mathrm{mg}$. The electrolyte is an aqueous solution of $1 \mathrm{M} \mathrm{H}_{2} \mathrm{SO}_{4}$. (a) CV curves of the AC-TC800-CFB at different scan rates. (b) GCD curves of the AC-TC800-CFB at different current densities. (c) Specific capacitances based on all electrode or only active material as a function at different scan rates, (d) specific capacitances calculated based on length, area, and volume. 

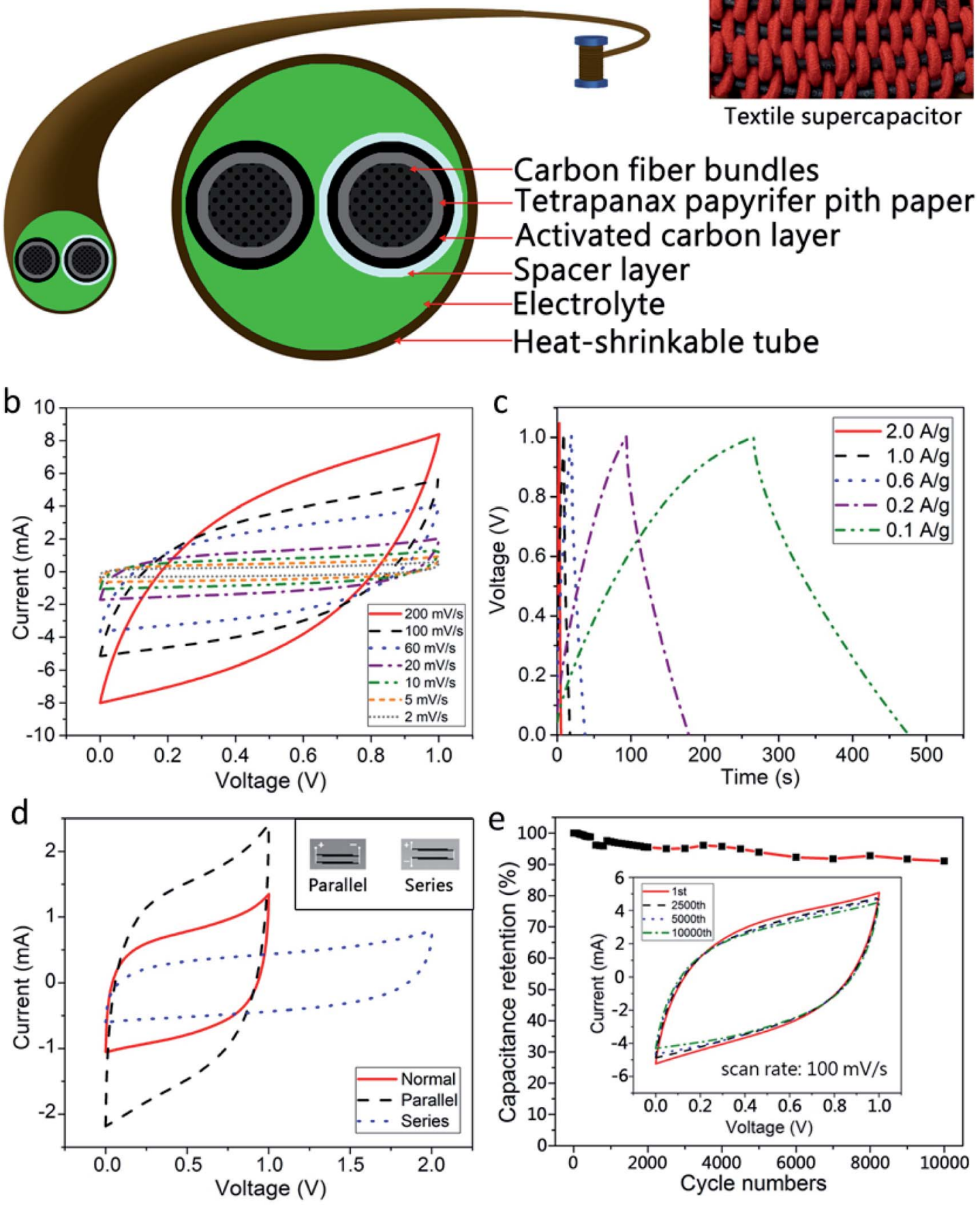

Fig. 7 Electrochemical performance of the $3 \mathrm{~cm}$ long FFSC using a gel electrolyte of $\mathrm{PVA}_{-} \mathrm{H}_{3} \mathrm{PO}_{4}$; (a) schematic representation of the FFSC; (b) CV curves measured at different scan rates; (c) GCD curves tested at different current densities; (d) electrochemical performance of the FFSCs arranged in series or in parallel; and (e) cyclic life test of the FFSC at a scan rate of $100 \mathrm{mV} \mathrm{s}^{-1}$ for 10000 cycles.

current collectors were wrapped with a TC pith paper, and the samples were carbonized at different temperatures followed by infiltration of AC slurry, and subsequently dried in an oven over night. A fiber electrode was then evenly wrapped with a nonwoven polyester fabric to avoid short circuits. Afterward, two electrodes wrapped with and without polyester were placed closely in parallel, inserted into a heat-shrinkable plastic tube, followed by the addition of PVA- $\mathrm{H}_{3} \mathrm{PO}_{4}$ gel electrolyte, and hot air was applied to shrink the tube.

The CV and GCD measurements of the FFSCs at different scan rates and current densities are depicted in Fig. $7 \mathrm{~b}$ and c, respectively. The FFSCs display quasi-rectangular CV curves and triangular waves with a small IR drop at the start of the discharge process especially at a lower scan rate, suggesting that 
the as-prepared FFSC is nearly an ideal EDLC with a low internal resistance.

The FFSCs are further integrated to achieve higher voltages or currents by connecting them in series or in parallel. The CV curves of two FFSCs connected in parallel or in series is displayed in Fig. 7d, with the inset depicting these two circuits. Compared with a single FFSC, the output current of a parallel circuit increased by a factor of two over the voltage range of 0 to $1.0 \mathrm{~V}$. The series circuit operated at a maximum voltage of $2.0 \mathrm{~V}$, which is two times the maximum output voltage of a single FFSC. The voltage profiles retain their original shapes, suggesting that the integratedsupercapacitor maintains stability without degradation of the excellent electrochemical properties of the AC-TC800-CFB FFSCs. The additivity of the capacitance by integrating the supercapacitor is important for high voltage or high current output.

A life test (Fig. 7e) reveals a high retention for the FFSC based on a $\mathrm{CV}$ test at a scan rate of $100 \mathrm{mV} \mathrm{s}^{-1}$. The specific capacitance of the AC-TC800-CFB FFSC remained approximately 91\% of its original value after 10000 cycles, indicating a long life cycle. In addition, it showed no severe damage such as exfoliation of the AC from the TC (SEM image not shown).

\subsection{Mechanical properties of the FFSC}

Capacitances of the FFSCs were tested at different bend angles to study the flexibility of the FFSCs. During the bending tests, the capacitance increased slightly at a high curvature due to squeezing of the gel into the pores of the FFSCs by the generated pressure (Fig. 8a). The CV curves of the FFSC display no obvious reduction in electrochemical performance even after 200 bending tests (Fig. 8b). The results indicate that the flexible FFSCs endure large-angle bending and repeated bending without loss of capacitance. The curves shown in Fig. 8c represent the specific capacitances calculated based on the electrodes or activated materials weights, whereas Fig. 8d illustrates the specific capacitance in terms of length, area, or volume. The results in Fig. 8 demonstrate that the FFSCs are flexible and strong enough to maintain their capacitance under different bending states and during repeating bending. This characteristic is beneficial for the utilization of the FFSCs for energy storage and power output in smart textile.

The CV curves of an unfolded and a folded FFSC and a schematic representation of the FFSC are shown in Fig. 9a and the inset, respectively. The CV curves of the folded and unfolded FFSCs are almost identical, indicating good mechanical properties of the fabricated supercapacitor. The Ragone plots of the FFSCs in terms of length and area are shown in Fig. 9b and c, respectively, with some published which using all-carbon material for the flexible fibrous supercapacitor results also included for comparison. The highest power density in Fig. 9b is $1.37 \mathrm{~mW} \mathrm{~cm}^{-1}$ (or $39.8 \mathrm{~mW} \mathrm{~cm}^{-2}$ ), whereas the energy density
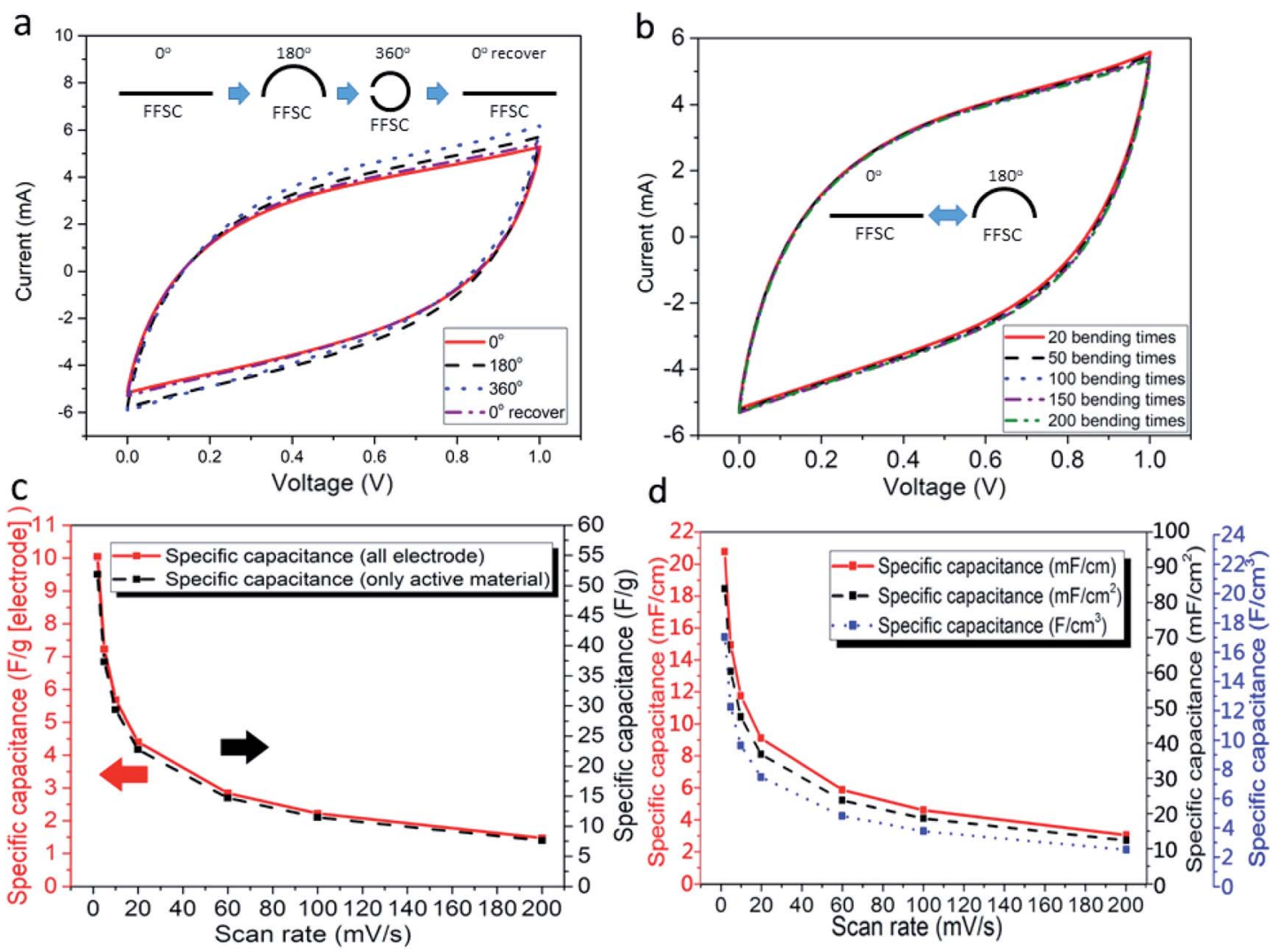

Fig. $8 \mathrm{CV}$ curves of the FFSC at (a) measurements performed under different bending angles and (b) different bending cycles; (c) specific capacitances of the FFSCs at different scan rates (based on the weights of electrodes or active materials); and (d) specific capacitances calculated in terms of length, area, and volume. 

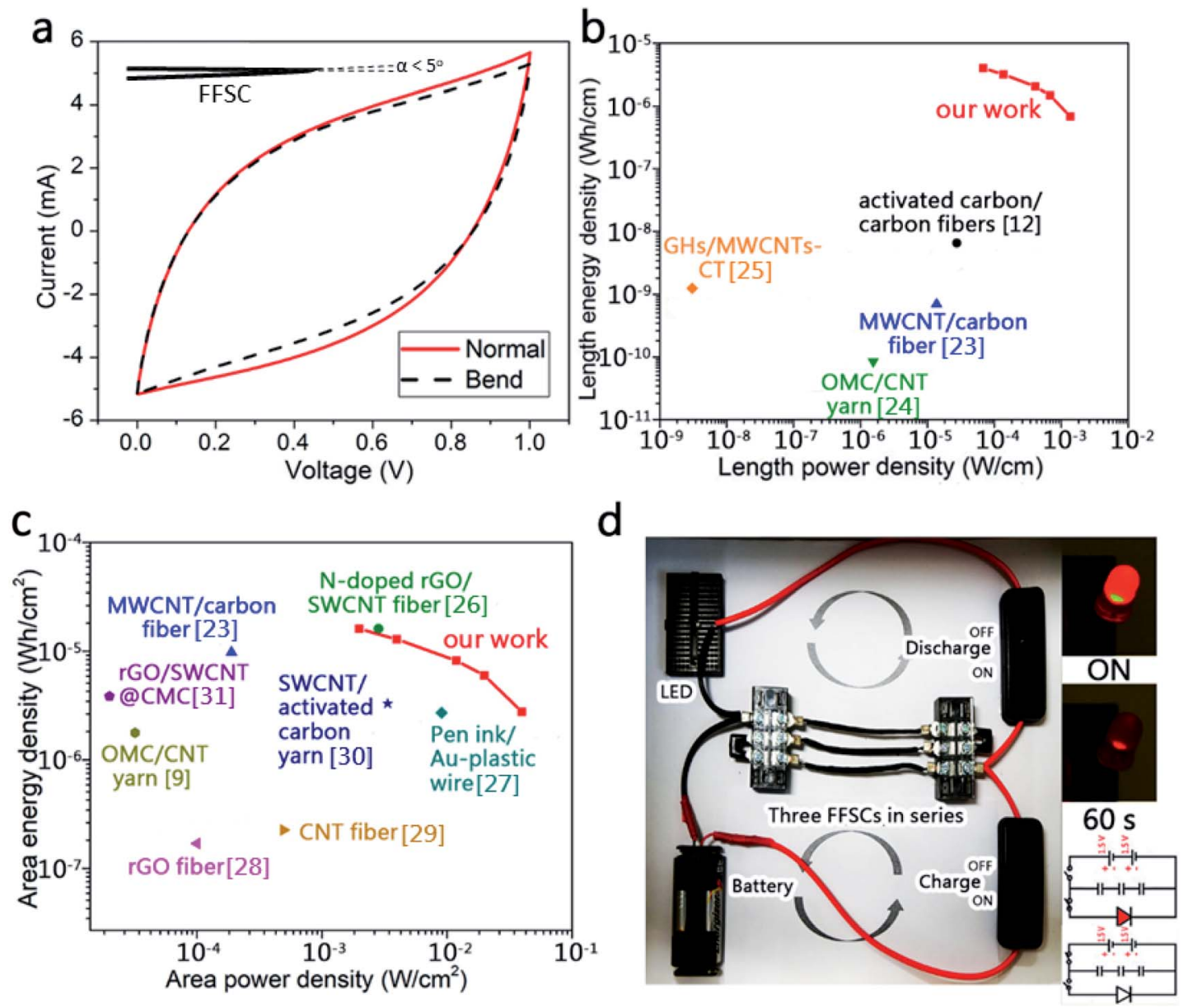

Fig. 9 (a) Dependence of the CV curves of the folded FFSC and the Ragone plot of the fabricated supercapacitors based on (b) length and (c)

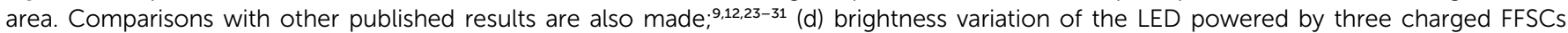
arranged in series. The inserted image in (d) is a schematic circuit diagram for charging the FFSCs and a lit LED in the beginning and after $60 \mathrm{~s}$.

in Fig. 9c is $0.68 \mu \mathrm{W} \mathrm{h} \mathrm{cm} \mathrm{cm}^{-1}$ (or $2.76 \mu \mathrm{W} \mathrm{h} \mathrm{cm}^{-2}$ ). The highest energy density of $3.98 \mu \mathrm{W} \mathrm{h} \mathrm{cm}{ }^{-1}$ (or $16.1 \mu \mathrm{W} \mathrm{h} \mathrm{cm}{ }^{-2}$ ) occurred at a power density of $0.07 \mathrm{~mW} \mathrm{~cm}^{-1}$ (or $1.99 \mathrm{~mW} \mathrm{~cm}^{-2}$ ). The energy and power densities at different current densities are presented in Table S1. $\dagger$ The system performance surpassed those previously reported.,.$^{\mathbf{9}, \mathbf{1 2 , 2 3 - 3 1}}$

Three FFSCs of length $3 \mathrm{~cm}$ each were arranged in series and charged for $10 \mathrm{~s}$. The FFSCs powered a red light-emitting diode (LED) for more than $1 \mathrm{~min}$ (Fig. 9d). The powered LED was very bright in the beginning, but the intensity slightly decreased after $60 \mathrm{~s}$.

\section{Conclusions}

In this study, high-performance FFSCs were fabricated using commercially available AC, CFBs, and TC as the primary materials. The AC-TC800-CFB electrodes fabricated through a simple and environmentally friendly process demonstrate extremely high capacitance even under bending. In the fabricated FFSCs, conductive CFBs and TC with a honeycomb-like structure served as the current collectors and substrates for
AC deposition, respectively. The excellent combination of AC, TC, and CFBs provided the FFSCs with a large effective area for ion transport and energy storage. The resultant specific length capacitance of $20.8 \mathrm{mF} \mathrm{cm}^{-1}$ at $2 \mathrm{mV} \mathrm{s}^{-1}$ is high specific length capacitance for all-carbon fiber supercapacitors. The FFSCs also exhibited an energy density of $16.1 \mu \mathrm{W} \mathrm{h} \mathrm{cm}^{-2}$ (or $3.98 \mu \mathrm{W}$ $\mathrm{h} \mathrm{cm}^{-1}$ ) and a power density of $1.99 \mathrm{~mW} \mathrm{~cm}^{-2}$ (or 0.07 $\mathrm{mW} \mathrm{cm}{ }^{-1}$ ), retaining an energy density of $2.76 \mu \mathrm{W} \mathrm{h} \mathrm{cm}{ }^{-2}$ (or $\left.0.56 \mathrm{~mW} \mathrm{~h} \mathrm{~cm}^{-1}\right)$ at a high power density $\left(39.8 \mathrm{~mW} \mathrm{~cm}^{-2}\right.$ or 1.37 $\mathrm{mW} \mathrm{cm}^{-1}$ ) after life tests for 10000 cycles. Additionally, we powered an LED light using three fabricated FFSCs arranged in series, to demonstrate the promising application of this system in smart textile applications. The fabrication method and fabricated FFSCs introduced in this work rely on environmentally friendly processes and commercially available carbon materials, indicating a great potential for utilization in future.

\section{Conflicts of interest}

There are no conflicts to declare. 


\section{Acknowledgements}

The authors thank the support from the Ministry of Science and Technology, Taiwan, under contract number MOST 104-2221-E007-029-MY3.

\section{References}

1 Q. Li, H. Cheng, X. Wu, C.-F. Wang, G. Wu and S. Chen, Enriched carbon dots/graphene microfibers towards highperformance micro-supercapacitors, J. Mater. Chem. A, 2018, 6(29), 14112-14119.

2 S. Xi, Y. Kang, S. Qu and S. Han, Flexible supercapacitors on chips with interdigital carbon nanotube fiber electrodes, Mater. Lett., 2016, 175, 126-130.

3 Y. Zhang, X. Zhang, K. Yang, X. Fan, Y. Tong, Z. Zhang, et al., Ultrahigh energy fiber-shaped supercapacitors based on porous hollow conductive polymer composite fiber electrodes, J. Mater. Chem. A, 2018, 6(26), 12250-12258.

4 X. Ye, Q. Zhou, C. Jia, Z. Tang, Z. Wan and X. Wu, A Knittable Fibriform Supercapacitor Based on Natural Cotton Thread Coated with Graphene and Carbon Nanoparticles, Electrochim. Acta, 2016, 206, 155-164.

5 S. Seyedin, E. R. S. Yanza and M. Razal Joselito, Knittable energy storing fiber with high volumetric performance made from predominantly MXene nanosheets, J. Mater. Chem. A, 2017, 5(46), 24076-24082.

6 H.-J. Chu, C.-Y. Lee and N.-H. Tai, Three-dimensional porous polyaniline/graphene-coated activated carbon fiber electrodes for supercapacitors, RSC Adv., 2016, 6(112), 111465-111471.

7 Y. Li, Z. Kang, X. Yan, S. Cao, M. Li, Y. Liu, et al., A facile method for the preparation of three-dimensional CNT sponge and a nanoscale engineering design for high performance fiber-shaped asymmetric supercapacitors, $J$. Mater. Chem. A, 2017, 5(43), 22559-22567.

8 L.-H. Tseng, C.-H. Hsiao, D. D. Nguyen, P.-Y. Hsieh, C.-Y. Lee and N.-H. Tai, Activated carbon sandwiched manganese dioxide/graphene ternary composites for supercapacitor electrodes, Electrochim. Acta, 2018, 266, 284-292.

9 Q. Yang, Z. Li, R. Zhang, L. Zhou, M. Shao and M. Wei, Carbon modified transition metal oxides/hydroxides nanoarrays toward high-performance flexible all-solid-state supercapacitors, Nano Energy, 2017, 41, 408-416.

10 S. Yan, J. Lin, P. Liu, Z. Zhao, J. Lian, W. Chang, et al., Preparation of nitrogen-doped porous carbons for highperformance supercapacitor using biomass of waste lotus stems, RSC Adv., 2018, 8(13), 6806-6813.

11 Q. Yang, Z. Xu, B. Fang, T. Huang, S. Cai, H. Chen, et al., MXene/graphene hybrid fibers for high performance flexible supercapacitors, J. Mater. Chem. A, 2017, 5(42), 22113-22119.

12 S. Zhai, W. Jiang, L. Wei, H. E. Karahan, Y. Yuan, A. K. Ng, et al., All-carbon solid-state yarn supercapacitors from activated carbon and carbon fibers for smart textiles, Mater. Horiz., 2015, 2(6), 598-605.

13 D. Yu, Q. Qian, L. Wei, W. Jiang, K. Goh, J. Wei, et al., Emergence of fiber supercapacitors, Chem. Soc. Rev., 2015, 44(3), 647-662.
14 Z. Wang, S. Qin, S. Seyedin, J. Zhang, J. Wang, A. Levitt, et al., High-Performance Biscrolled MXene/Carbon Nanotube Yarn Supercapacitors, Small, 2018, 14(37), e1802225.

15 D. Harrison, F. Qiu, J. Fyson, Y. Xu, P. Evans and D. Southee, A coaxial single fibre supercapacitor for energy storage, Phys. Chem. Chem. Phys., 2013, 15(29), 12215-12219.

16 X. Deng, S. Zhu, J. Li, L. Ma, F. He, E. Liu, et al., Ball-in-cage nanocomposites of metal-organic frameworks and threedimensional carbon networks: synthesis and capacitive performance, Nanoscale, 2017, 9(19), 6478-6485.

17 W. Huang, H. Zhang, Y. Huang, W. Wang and S. Wei, Hierarchical porous carbon obtained from animal bone and evaluation in electric double-layer capacitors, Carbon, 2011, 49(3), 838-843.

18 W. Xing, C. C. Huang, S. P. Zhuo, X. Yuan, G. Q. Wang, D. Hulicova-Jurcakova, et al., Hierarchical porous carbons with high performance for supercapacitor electrodes, Carbon, 2009, 47(7), 1715-1722.

19 Y. J. Oh, J. J. Yoo, Y. I. Kim, J. K. Yoon, H. N. Yoon, J.-H. Kim, et al., Oxygen functional groups and electrochemical capacitive behavior of incompletely reduced graphene oxides as a thin-film electrode of supercapacitor, Electrochim. Acta, 2014, 116, 118-128.

20 Y. He, Y. Zhang, X. Li, Z. Lv, X. Wang, Z. Liu, et al., Capacitive mechanism of oxygen functional groups on carbon surface in supercapacitors, Electrochim. Acta, 2018, 282, 618-625.

21 H. Cao, X. Peng, M. Zhao, P. Liu, B. Xu and J. Guo, Oxygen functional groups improve the energy storage performances of graphene electrochemical supercapacitors, RSC Adv., 2018, 8(6), 2858-2865.

22 A. Sanchez-Sanchez, A. Martinez de Yuso, F. L. Braghiroli, M. T. Izquierdo, E. D. Alvarez, E. Pérez-Cappe, et al., Sugarcane molasses as a pseudocapacitive material for supercapacitors, RSC Adv., 2016, 6(91), 88826-88836.

23 V. T. Le, H. Kim, A. Ghosh, J. Kim, J. Chang, Q. A. Vu, et al., Coaxial Fiber Supercapacitor Using All-Carbon Material Electrodes, ACS Nano, 2013, 7(7), 5940-5947.

24 J. Ren, W. Bai, G. Guan, Y. Zhang and H. Peng, Flexible and weaveable capacitor wire based on a carbon nanocomposite fiber, Adv. Mater., 2013, 25(41), 5965-5970.

25 Q. Zhou, C. Jia, X. Ye, Z. Tang and Z. Wan, A knittable fibershaped supercapacitor based on natural cotton thread for wearable electronics, J. Power Sources, 2016, 327, 365-373.

26 D. Yu, K. Goh, H. Wang, L. Wei, W. Jiang, Q. Zhang, et al., Scalable synthesis of hierarchically structured carbon nanotube-graphene fibres for capacitive energy storage, Nat. Nanotechnol., 2014, 9(7), 555-562.

27 Y. Fu, X. Cai, H. Wu, Z. Lv, S. Hou, M. Peng, et al., Fiber supercapacitors utilizing pen ink for flexible/wearable energy storage, Adv. Mater., 2012, 24(42), 5713-5718.

28 Y. Meng, Y. Zhao, C. Hu, H. Cheng, Y. Hu, Z. Zhang, et al., All-graphene core-sheath microfibers for all-solid-state, stretchable fibriform supercapacitors and wearable electronic textiles, Adv. Mater., 2013, 25(16), 2326-2331.

29 P. Xu, T. Gu, Z. Cao, B. Wei, J. Yu, F. Li, et al., Carbon Nanotube Fiber Based Stretchable Wire-Shaped Supercapacitors, Adv. Energy Mater., 2014, 4(3), 1300759. 
30 Q. Meng, H. Wu, Y. Meng, K. Xie, Z. Wei and Z. Guo, Highperformance all-carbon yarn micro-supercapacitor for an integrated energy system, Adv. Mater., 2014, 26(24), 41004106.
31 L. Kou, T. Huang, B. Zheng, Y. Han, X. Zhao, K. Gopalsamy, et al., Coaxial wet-spun yarn supercapacitors for high-energy density and safe wearable electronics, Nat. Commun., 2014, 5,3754 . 